\title{
REFERENCES
}

Bacher, J. E. \& Allen, F. W. (1950a). J. biol. Chem. 184, 511.

Bacher, J. E. \& Allen, F. W. (1950b). J. biol. Chem. 183, 633.

Bernheimer, A. W. \& Rodbart, M. (1948). J. exp. Med. 88, 149.

Carter, C. E. (1950). J. Amer. chem. Soc. 72, 2811.

Fletcher, W. E., Gulland, J. M. \& Jordan, D. O. (1944). J. chem. Soc. p. 33.

Greenstein, J. P., Carter, C. E. \& Chalkley, H. W. (1947). Cold Spr. Harb. Symp. quant. Biol. 12, 64.

Kunitz, M. (1940). J. gen. Physiol. 25, 15.
Magasanik, B. \& Chargaff, E. (1951). Biochim. Biophys. Acta, 7, 396.

Markham, R. \& Smith, J. D. (1951). Nature, Lond., 168, 406.

Markham, R. \& Smith, J. D. (1952a). Biochem. J. 52, 552.

Markham, R. \& Smith, J. D. (1952b). Biochem. J. 52, 558.

Markham, R. \& Smith, K. M. (1949). Parasitology, 39, 330.

Schmidt, G., Cubiles, R., Zöllner, N., Hecht, L., Strickler, N., Seraidarian, K., Seraidarian, M. \& Thannhauser, S. J. (1951). J. biol. Chem. 192, 715.

Tennent, H. G. \& Vilbrant, C. F. (1943). J. Amer. chem. Soc. $65,424$.

\section{The Orobanche Germination Factor}

\section{CONCENTRATION OF THE FACTOR BY COUNTER-CURRENT DISTRIBUTION}

\author{
By R. BROWN, A. D. GREENWOOD, A. W. JOHNSON, A. R. LANSDOWN, \\ A. G. LONG AND N. SUNDERLAND \\ Botany Department, University of Leeds, and Chemical Laboratory, University of Cambridge
}

(Received 27 February 1952)

The chromatographic purification of crude concentrates of the Orobanche germination stimulant, particularly partition chromatography on cellulose, has been described in an earlier paper (Brown, Greenwood, Johnson, Long \& Tyler, 1951b). The most active preparations thus obtained had activity values (Brown, Greenwood, Johnson \& Long, 1951 a) of 1-2 $\times 10^{5}$, and it seemed possible that they contained a high percentage of the pure stimulant. However, as these preparations were invariably resinous and as no convenient physical property of the stimulant was known by which its purity could be gauged, other methods of purification have been investigated to ascertain whether concentrates could be obtained with even higher activity values and possibly in a crystalline form.

Much of the present paper is concerned with purification of the Orobanche germination factor by partitioning between immiscible solvents, the choice of solvents being limited on the basis of earlier stability studies (Brown et al. 1951b) to those boiling below $120^{\circ}$ and neither strongly basic nor acidic.

In our earlier studies it was shown that the stimulant adsorbed on charcoal could best be eluted with chloroform-methanol and it has now been found that considerable purification of these crude eluates can be achieved by a further extraction of their aqueous solutions with ethyl acetate. This step has been included in all of our later purifications. Ethyl acetate was slightly superior to chloroform or ether for this extraction step.
The partition method of purification was extended to the use of counter-current methods, and many solvent systems were tried before a satisfactory distribution ratio of the active stimulant was achieved between the two immiscible phases. Some idea of the partition coefficient of a compound between heterogeneous solvent phases can be obtained from preliminary paper-strip chromatograms (Brown et al. 1951b). The relationship of the $R_{F}$ value in partition chromatography to the partition coefficient has been discussed by Martin \& Synge (1941), by Consden, Gordon \& Martin (1944) and by Craig (1950).

The mixture tert.-butanol (4)-light petroleum (b.p. $60-80^{\circ} ; 5$ )-acetone (4)-water (2) was eventually devised and this gave an appreciable concentration of the active material in the centre tubes of the counter-current apparatus, i.e. the partition was approximately equal between the two phases. tert.-Butanol was selected as the alcoholic component in order to cut down any esterification of lactone or acid groupings believed to be present in the molecule of the germination factor. The use of buffered solutions in the counter-current extractions to suppress such undesirable changes seemed inadvisable in view of the instability of the factor in alkaline or strongly acid solutions and the impossibility of carrying out the biological test in the presence of buffer solutions of the usual concentrations.

The purified stimulant obtained either by chromatography (Brown et al. 1951b) or by extrac. tion methods was only slightly soluble in water, and 
for testing purposes the product was dissolved in a little methanol and a large volume of water added. The methanol was then removed under reduced pressure and the resulting emulsion used for the assay. Such emulsions could not be separated in the centrifuge so that fractional precipitation offered little promise as a means of purification.

The progress of isolation and purification of a biologically active material is determined to a large extent by the speed and accuracy of the biological testing. In this case the results of any particular

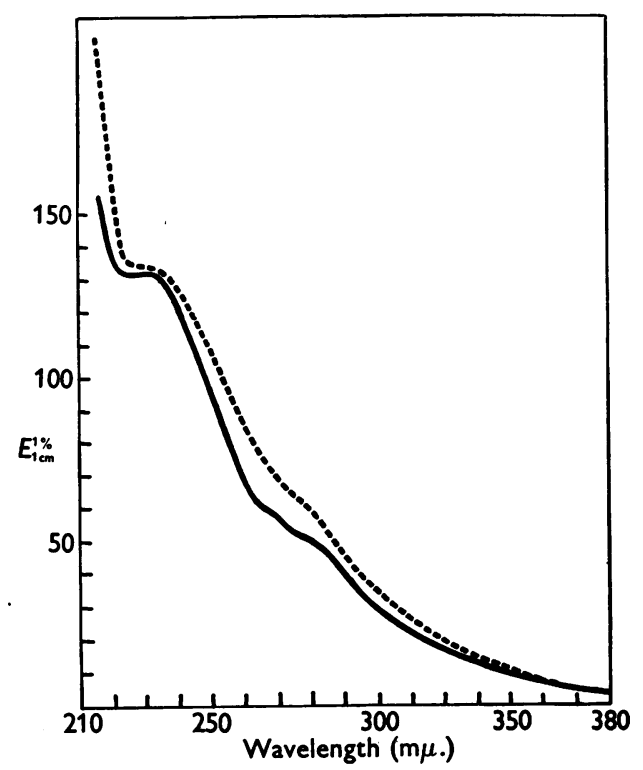

Fig. 1. Ultraviolet absorption spectrum of the crude Orobanche germination stimulant (activity value, 63 000). —_ ethanol solution; - . . . - aqueous solution.

test were not available before 7 days and consequently characteristic physical properties of the active material were sought in order that the various fractions might be assessed more rapidly.

The ultraviolet absorption spectrum (Fig. 1) of the crude concentrate before counter-current purification or even after distribution between chloroform and water did not reveal any characteristic features other than an arrest at 2300-2350 A. and a slight inflexion at $2800 \mathrm{~A}$. However, after purification by the four-component system, tert.butanol-petroleum (b.p. 60-80 ${ }^{\circ}$-acetone-water as described above, the ultraviolet absorption spectrum of the most active fraction exhibited a distinct maximum at $2450 \mathrm{~A} .\left(E_{1 \mathrm{~cm} .}^{1 \%}=170\right)($ Fig. 2$)$, and it seems probable that this ultraviolet absorption is a feature of the biologically active material.

Like the Striga germination factor (Brown, Johnson, Robinson \& Tyler, 1952) the Orobanche factor can be distilled under high vacuum. Fig. 4 shows the results of a typical fractionation, and it will be seen that most of the active material distils at temperatures around $100^{\circ}$ at a pressure of $10^{-5} \mathrm{~mm}$. Although considerable loss of total activity is incurred in these distillations, the fact that the stimulant can be distilled at all is clear indication that the anhydrous concentrate is much more stable than its aqueous solutions. The ultraviolet absorption spectrum of the biologically active fraction of the distillate again showed a distinct maximum at $2450 \mathrm{~A}$. $\left(E_{1 \mathrm{~cm} .}^{1 \%}=160\right)$.

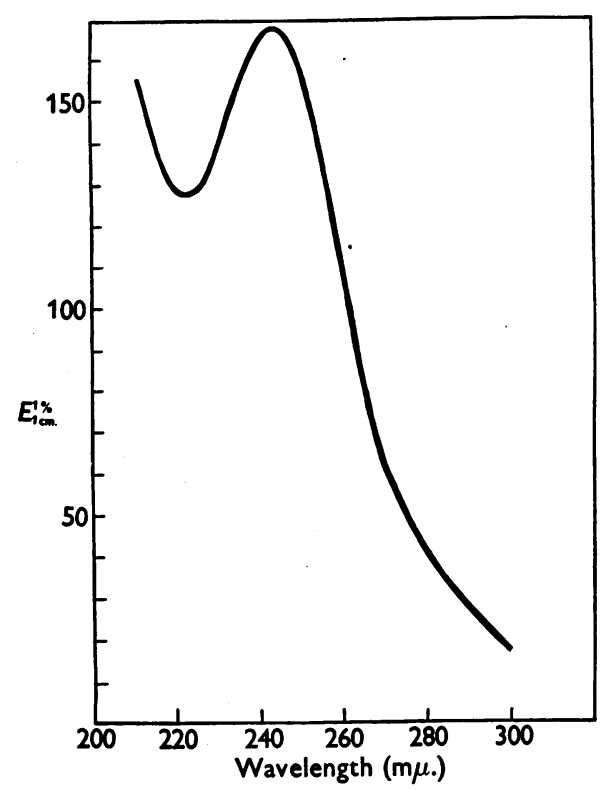

Fig. 2. Ultraviolet absorption spectrum of purified Orobanche germination stimulant (activity value, 100000 ) in ethanol.

\section{EXPERIMENTAL}

Concentration of the germination factor by solvent extraction of the crude concentrates. The crude eluate $(83.7 \mathrm{mg}$.) obtained from the charcoal (Brown et al. 1951 a) was dissolved in water (20 ml.; activity of solution, 10600$)$ and extracted with ethyl acetate $(5 \times 100 \mathrm{ml}$.). The solvent was removed from the combined extracts below $40^{\circ}$ or preferably by freeze-drying and the water-soluble fraction $(6.5 \mathrm{mg}$.) of the residue (16.2 mg.) tested for activity (122 000; recovered activity, $90 \%$ ). Similar experiments were carried out using $\mathrm{CHCl}_{3}$ (85-89\% activity recovery) and diethyl ether $\mathbf{( 7 5} \%$ activity recovery).

Counter-current extraction of concentrates of the germination factor. The material used for the counter-current extractions was obtained by eluting the charcoal with $\mathrm{CHCl}_{3}$-methanol (Brown et al. 1951 $a$ ) and then extracting an aqueous solution of the product with ethyl acetate as described above. A 25-tube counter-current apparatus (Craig \& Post, 1949) was used, and after the distribution the combined phases from each tube were evaporated to dryness, the efficiency of 
the separation being assessed by determinations of the weight, optical density and biological activity of each fraction. Results using the 4-component, 2-phase system, water (2)-petroleum (b.p. $\left.60-80^{\circ} ; 5\right)$-tert.-butanol (4)-acetone (4) are expressed in Fig. 3.

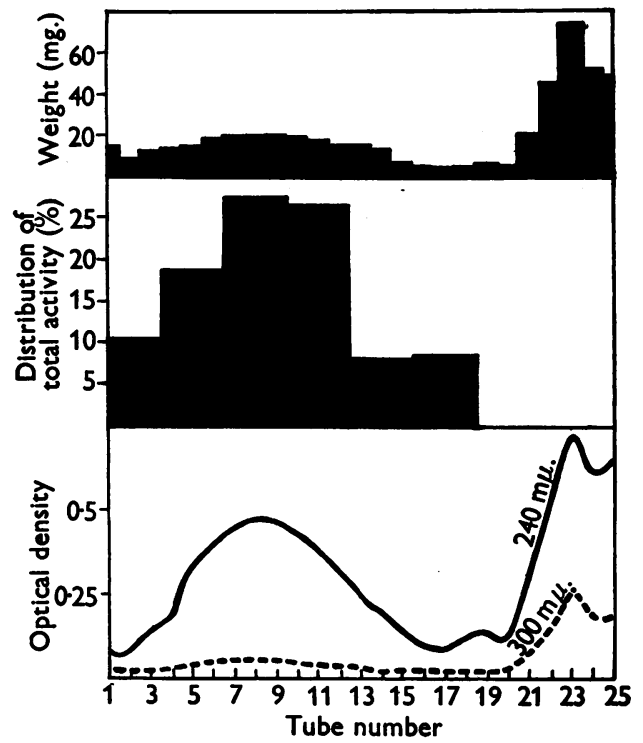

Fig. 3. Counter-current distribution of a concentrate of the Orobanche germination factor between tert.-butanolpetroleum (b.p. $60-80^{\circ}$ )-acetone-water.

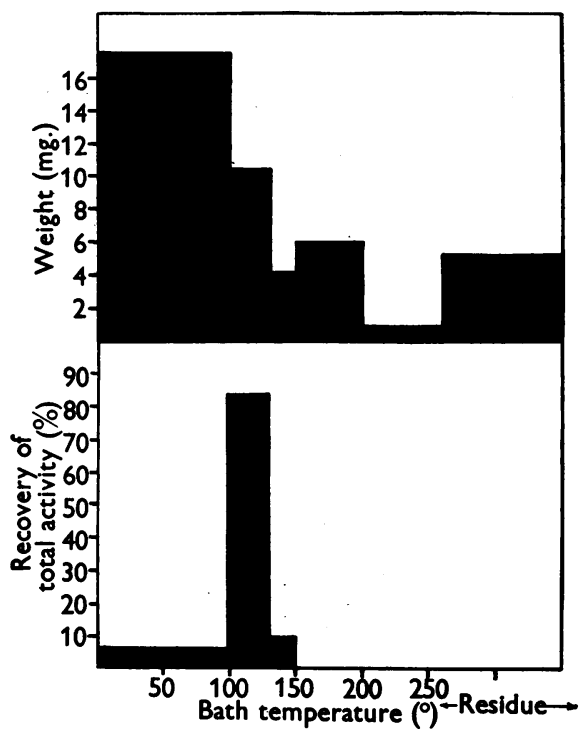

Fig. 4. Distillation of a concentrate of the Orobanche germination factor at $10^{-5} \mathrm{~mm}$.

Distillation of the germination factor. The crude concentrate (38.4 mg.; activity 5600) was subjected to high vacuum distillation at $1 \times 10^{-5} \mathrm{~mm}$. with a very short path length, and several fractions were taken off on a cold finger, the bath temperature being raised at the rate of $20^{\circ} / \mathrm{hr}$. The weight and activity of each fraction were determined and the results are expressed in Fig. 4.

Titration of the germination factor. The concentrate (18 mg.; activity, 67 000) was dissolved in 0.1 N-tetramethylammonium hydroxide (3.0 ml.) and kept for 2 days at room temperature with exclusion of $\mathrm{CO}_{2}$. The solution was agitated by the passage of a stream of purified $\mathrm{N}_{2}$ through it and titrated against $0.2 \mathrm{~N}-\mathrm{HCl}$ in an electrometric apparatus with a glass electrode. From the amount of acid $(0.89 \mathrm{ml}$.) required to neutralize the excess alkali, the equivalent weight was calculated to be 148 .

In a further experiment the same concentrate (18 mg.) was dissolved in $0.1 \mathrm{~N}-\mathrm{NaOH}$ and the solution heated at $100^{\circ}$ for $10 \mathrm{~min}$., cooled and titrated as before. This experiment gave a value of 133 for the equivalent weight. In each case the $\mathrm{pH}$ of the alkaline solution of the concentrate decreased on keeping.

\section{DISCUSSION}

Counter-current extraction is a useful method of purification in the case of the Orobanche germination stimulant, the most active material thus produced having an activity value of the same order $(250000)$ as that obtained by partition chromatography on columns of cellulose (Brown et al. 1951b), and it seems reasonable to assume that both 'materials contain an appreciable amount of the pure stimulant. From the experimental point of view the counter-current method is slightly easier to carry out than the chromatographic method and has been adopted in most of the recent work. The preferred method of purification of the concentrate at the present time therefore comprises (i) adsorption on charcoal, (ii) elution with chloroform-methanol, (iii) extraction of an aqueous solution of the product with ethyl acetate or, better, washing an ethyl acetate solution with water, (iv) counter-current distribution between chloroform and water, ( $v$ ) counter-current distribution using the tert.-butanolpetroleum (b.p. $60-80^{\circ}$ )-acetone-water mixture.

The fractional distillation of the concentrates under high vacuum with a short path length also has resulted in a marked concentration of the factor in one fraction. This is a somewhat surprising result in view of the instability to heat of solutions of the concentrates (Brown et al. 1951 a) in polar solvents, especially water, and it therefore seems that the solvents accelerate deactivation. The rate of deactivation of slightly alkaline aqueous solutions of the factor seemed to be independent of the presence or absence of oxygen.

Only preliminary evidence is available on the chemical nature of the Orobanche germination factor at the present time. Moreover, in the absence of the pure factor, the necessity of working only with noncrystalline concentrates makes it very difficult to differentiate between the properties of the factor 
itself and those of any impurities which might be present. However, on the basis of the comparable activity values of purified concentrates obtained by partition chromatography or by counter-current extraction, the products have been used for preliminary degradative work. Sulphur, phosphorus and halogens were absent, and the small nitrogen values (about $0.5 \%$ ) obtained in several analyses are unlikely to be significant. Carbon and hydrogen determinations on various concentrates (activity, $1-2 \times 10^{5}$ ) have given values of $\mathrm{C}, 59.5-62.0 ; \mathrm{H}$, $7.6-8.7 \%\left(\mathrm{C}_{10} \mathrm{H}_{18} \mathrm{O}_{4}\right.$ requires $\mathrm{C}, 59.4 ; \mathrm{H}, 8.9 \%$; $\mathrm{C}_{11} \mathrm{H}_{16} \mathrm{O}_{4}$ requires $\mathrm{C}, 62.3 ; \mathrm{H}, 7 \cdot 6 \%$ ) after drying at a pressure of $10^{-2} \mathrm{~mm}$. and room temperature over phosphorus pentoxide overnight.

The concentrates are unreactive to Fehling solution, periodate, Schiff reagent and Millon reagent and do not decolorize bromine water. On the other hand, they reduce Tollens reagent and instantly decolorize neutral permanganate in the cold. They are optically inactive (in one case a solution of a sample of concentrate $(56 \mathrm{mg}$.) in chloroform $(3 \mathrm{ml}$.$) gave [\alpha]_{D}+1 \cdot 1^{\circ} \pm 0 \cdot 6^{\circ}$ but generally the rotation was imperceptible), give no colour with ferric chloride and only a slight yellow precipitatê with 2:4-dinitrophenylhydrazine. Evidence for a lactone, ester or other potential acid group comes from a positive hydroxamate colour reaction (Feigl, 1947) and the marked fall in $\mathrm{pH}$ on keeping freshly prepared alkaline solutions of the factor. The infrared spectrum of a purified concentrate (activity, $1 \times 10^{5}$ ) gives evidence of a hydroxyl group (band at $2.92 \mu$.), two ester (or $\delta$-lactone) groups (bands at 5.77 and 5.82 $\mu$.) and also a methyl group (band at $7 \cdot 27 \mu$.) and a double bond (band at $6.04 \mu$.).

It is evident that the Orobanche germination factor has some features in common with the Striga germination factor described in another series of papers (Brown, Johnson, Robinson \& Todd, 1949;
Brown et al. 1952). This is apparent from the closely similar methods of extraction applicable in each case, and from the closely related physical and chemical properties of each of the concentrates. This supposition has been supported by the results of testing the effect of the Orobanche germination factor on Striga seeds and vice versa when definite germination effects were obtained in each case. It is also possible that these germination factors may bear some relation to the potato eel-worm hatching factor already examined by Todd and his colleagues (Calam, Raistrick \& Todd, 1949 and succeeding papers) although active concentrates of the latter showed little effect on Orobanche or Striga seeds. The evidence for the free carboxyl group in the eelworm hatching factor is more definite than in the plant germination factors. Nevertheless, any relationship between these compounds would be of far-reaching biological significance.

\section{SUMMARY}

1. The purification of concentrates of the Orobanche germination factor using extraction techniques, including counter-current methods, is described. The most active concentrates so obtained have activity values comparable to those obtained by partition chromatography.

2. The germination factor can be distilled at very low pressures.

3. Some chemical properties of the purified concentrates are described.

We are greatly indebted to Prof. A. R. Todd, F.R.S., for his interest and advice throughout this work. We also thank the Agricultural Research Council for supporting this project, and Glaxo Laboratories Ltd., and the Department of Scientific and Industrial Research for grants to A.G.L. and A.R.L. respectively. The determination of the infrared spectrum was carried out by Dr R.N. Haszeldine to whom we accord our thanks.

\section{REFERENCES}

Brown, R., Greenwood, A. D., Johnson, A. W. \& Long, A. G. $(1951 a)$. Biochem. J. 48, 559.

Brown, R., Greenwood, A. D., Johnson, A. W., Long, A. G. \& Tyler, G. J. (1951 b). Biochem. J. 48, 564 .

Brown, R., Johnson, A. W., Robinson, E. \& Todd, A. R. (1949). Proc. Roy. Soc. B, 136, 1.

Brown, R., Johnson, A. W., Robinson, E. \& Tyler, G. J. (1952). Biochem. J. 50, 596.

Calam, C. T., Raistrick, H. \& Todd, A. R. (1949). Biochem. $J .45,513$ and succeeding papers.
Consden, R., Gordon, A. H. \& Martin, A. J. P. (1944). Biochem. J. 38, 224.

Craig, L. C. (1950). Anal. Chem. 22, 1347.

Craig, L. C. \& Post, O. (1949). Anal. Chem. 21, 500.

Feigl, F. (1947). Qualitative Analysis by Spot Tests, p. 358. New York: Elsevier Publishing Company Inc.

Martin, A. J. P. \& Synge, R. L. M. (1941). Biochem. J. 35, 1358. 